Artigo de revisão

\title{
INFLUÊNCIA DOS POLUENTES AMBIENTAIS NA INCIDÊNCIA DE DERMATITE ATÓPICA E OS POSSÍVEIS ATIVOS DERMATOLÓGICOS PARA O DESENVOLVIMENTO DE DERMOCOSMÉTICOS ANTIPOLUIÇÃO
}

\author{
Autor: Amanda Pereira Ribeiro', Bianca Farias Leite', Bianca Sayuri Nakasone ${ }^{1}$, Giovanna de \\ Sousa Pimentel'1, Mariana Antoniassi Soares'1, Valéria Maria de Souza Antunes ${ }^{2, A}$
}

1Universidade Anhembi Morumbi. Acadêmica em Farmácia. ${ }^{2}$ Docente da Universidade Anhembi Morumbi.

\section{Informações do artigo}

Palavras Chave:

Dermatite atópica;

Imunologia da pele;

Poluição ambiental;

Poluentes; Ativos

Antipoluição.

\begin{abstract}
Resumo
A Dermatite Atópica é uma doença inflamatória crônica localizada no tecido cutâneo e possui maior incidência observada na primeira fase da infância. Um dos fatores para o surgimento da doença é a predisposição genética e o outro são os estímulos externos. A Dermatite Atópica não possui mecanismo de ação específico, mas observa-se que os fatores intrínsecos e extrínsecos podem estimular o seu desencadeamento. Os fatores intrínsecos estão relacionados com a predisposição genética e como o organismo reage a diferentes estímulos endógenos. Fatores externos, como os agentes poluentes, atuam com alto poder para desenvolver ou provocar o agravamento da Dermatite Atópica, pois a exposição da pele à estímulos e poluentes ambientais acabam causando o desequilíbrio entre oxidantes e antioxidantes e, este desequilíbrio, provoca o estresse oxidativo que por fim gera o agravamento dos sintomas. A poluição da atmosfera proporciona danos de lipídios, proteínas e danos no DNA. Deste modo, é possível relacionar a Dermatite Atópica com a poluição e suas partículas. É possível sugerir ativos dermatológicos para uso em formulações para a doença em questão, associando ativos antipoluição. Tais ativos possuem origens diversas e suas propriedades podem ser direcionadas para formulações de uso tópico na pele.
\end{abstract}

AAutor correspondente:

Valéria Maria de Souza Antunes - e-mail: valeriabelaclara@gmail.com - ORCID: https://orcid.org/0000-0002-4156-4879.

DOI: https://doi.org/10.31415/bjns.v2i3.63 - Artigo recebido em: 18 de junho de 2019 ; aceito em 09 de Julho de 2019 ; publicado em 30 de setembro de 2019. Brazilian Journal of Natural Sciences, Vol. 2, N.3, setembro 2019. Disponível online a partir de 30 de setembro de 2019, ISSN 2595-0584. www.bjns.com.br. Todos os autores contribuíram igualmente com o artigo. Os autores declaram não haver conflito de interesse. Este é um artigo de acesso aberto sob a licença CC - BY: http://creativecommons.org/licenses/by/4.0 


\section{Article ID}

Keywords:

Atopic dermatitis; Skin

immunology; Environment

pollution; Pollutants;

Antipollution Ingredients.

\begin{abstract}
Atopic Dermatitis is a chronic inflammatory disease located in the cutaneous tissue and possesses its higher incidence observed in the first phase of childhood. One of the factors for the onset of the disease is genetic predisposition and external stimuli. Atopic Dermatitis has no specific action mechanism, but it is observed that intrinsic and extrinsic factors can stimulate its onset. The intrinsic factors are related to the genetic predisposition and how the organism reacts to different endogenous stimuli. External factors such as pollutant agents perform with high power to develop or cause escalation of Atopic Dermatitis because the skin's exposure to stimuli and environmental pollutants end up causing the imbalance between oxidants and antioxidants and this imbalance causes oxidative stress that, eventually, generates the worsening of symptoms. Air pollution causes damage to lipids, proteins, and DNA detrimental. Thus, it is possible to relate Atopic Dermatitis to pollution and its particles. Therefore, it is possible to suggest the use of dermatological ingredients, in association to antipollution ingredients, in formulations to the disease at stake. Those ingredients have different origins and their properties can be directed for topical use in skin.
\end{abstract}

\section{Introdução}

A pele humana é o maior órgão do corpo humano e sua maior função é a proteção contra agressões externas. A radiação solar sempre foi vista como o principal motivo para problemas relacionados à pele, como manchas, inflamações e câncer. No entanto, cresce o número de estudos que apontam que os poluentes do ar, principalmente em grandes centros urbanos, têm relação com a incidência de patologias cutâneas, com relevância para a Dermatite Atópica. A liberação de poluentes químicos produzidos pela combustão dos combustíveis fósseis provenientes dos veículos tende a se concentrar na atmosfera passando por reações químicas, quebrando as moléculas de oxigênio pela ação dos raios ultravioleta e formando o ozônio (O3).

O material particulado são partículas muito finas de líquidos ou sólidos que estão suspensos no ar e podem ser de materiais inorgânicos ou orgânicos. As fontes são desde a queima de biomassa vegetal até a pavimentação de vias. Segundo diversos estudos, as partículas tóxicas penetram a pele através dos folículos pilosos.

A permeação de substâncias indesejadas está relacionada com a deficiência do manto hidro lipídico cuja propriedade maior é a formação de uma película protetora na pele, não só protegendo-a de substâncias indesejáveis, mas, evitando doenças como a Dermatite Atópica.

\section{Material e método}

A revisão foi baseada em fontes de artigos científicos relacionados à incidência da Dermatite Atópica, mecanismo de ação da poluição e ativos com ação antipoluição. Os artigos utilizados para a elaboração da revisão foram retirados de banco de dados como: Pubmed e SciELO. As palavras chaves utilizadas foram: Dermatite atópica; Manto hidro lipídico; Pele Sensível; Imunologia da pele; Poluição ambiental; Poluentes; Ativos Antipoluição.

A elaboração da revisão bibliográfica utilizou 33artigos publicados no período de 2011 a 2019 e 1 livro utilizado para obter informações relacionadas aos ativos dermatológicos para o desenvolvimento das formulações sugeridas.

\section{Discussão}

\section{Manto hidro lipídico}

O manto hidro lipídico corresponde a uma película com a função de proteger e hidratar a pele, cuja 
composição possui lipídios (ácidos graxos, ceramidas e colesterol) associado com o material originado das glândulas sebáceas e glândulas sudoríparas e que se aloja na camada córnea. Desta forma, esta emulsão natural é depositada na superfície cutânea. $\mathrm{O}$ manto possui a função de manter a hidratação da pele criando uma barreira contra invasões e contra a perda de água transepidermal, podendo auxiliar a hidratação cutânea através da oclusão ou através de efeito hidrofílico [1].

O manto hidro lipídico apresenta fragilidade a fatores extrínsecos e intrínsecos podendo ocorrer a penetração de substâncias indesejadas causando irritações na pele. Atualmente encontram-se no mercado uma série de dermocosméticos voltados para a manutenção do manto hidro lipídico, cujo intuito é melhorar a condição cutânea e aumentar a quantidade de água no extrato córneo [2].

Os poluentes atmosféricos induzem alterações severas das funções normais dos lipídios, ácido desoxirribonucleico e/ou proteínas na pele humana via dano oxidativo, levando ao envelhecimento extrínseco da pele, condições inflamatórias ou alérgicas como Dermatite de Contato D.C, Dermatite Atópica D.A, psoríase, acne e câncer de pele [3].

Os poluentes encontrados no ar ambiente podem ser classificados como: poluentes orgânicos persistente, material particulado, metais pesados, poluentes gasosos e poluentes tóxicos [4].

Apesar de existirem diversos tipos de poluição física, químico e até biológico, a poluição atmosférica é a mais comum, e é responsável por diversos tipos de distúrbios da pele [5].

Tabela 1. Levantamento dos tipos de poluentes.

\begin{tabular}{|c|l|}
\hline Poluentes & \multicolumn{1}{c|}{ Descrição } \\
\hline $\begin{array}{c}\text { Orgânicos } \\
\text { persistentes }\end{array}$ & $\begin{array}{l}\text { É caracterizado como um poluente resistente à degradação ambiental e, quando } \\
\text { presentes nos alimentos consumidos encontram-se em concentrações 100 vezes } \\
\text { superiores as das encontradas em águas. Não é degradado no trato gastrointestinal, } \\
\text { causando a bioacumulação e biomagnificação em humanos e animais. Exemplos } \\
\text { comuns de poluentes orgânicos persistentes são as dioxinas, pesticidas e } \\
\text { bifenilas policloradas que geralmente são encontradas em centros urbanos em } \\
\text { desenvolvimento. }\end{array}$ \\
\hline Gasosos & $\begin{array}{l}\text { Os poluentes gasosos mais comuns são NO, CO, SO2, Ozônio e compostos orgânicos } \\
\text { voláteis, são provenientes da combustão de combustíveis fósseis. }\end{array}$ \\
\hline Material & $\begin{array}{l}\text { É a mistura de gotículas sólidas e/ou líquidas suspensa em gás. Estão presentes no } \\
\text { solo e poeira e são classificadas como partículas grosseiras. Já as partículas finas } \\
\text { são provenientes de usinas de energia, exaustão de automóveis e fogueiras. Existem } \\
\text { também as partículas ultrafinas que estão relacionadas com os atuais motores movidos } \\
\text { a diesel. As partículas ultrafinas emergem de forma mais abundante em ambientes } \\
\text { industriais e urbanos podendo causar risco a saúde devido a sua penetração através } \\
\text { de junções estreitas endoteliais, deste modo obtendo um acesso direto vascular e } \\
\text { sistêmico. O material particulado é conhecido por carregar componentes tóxicos em } \\
\text { sua superfície incluindo carcinógenos, ácidos, bactérias e metais. São classificadas de } \\
\text { acordo com o diâmetro aerodinâmico das partículas: Partículas Totais em Suspensão } \\
\text { (PTS) são menores ou iguais a 50 } \mu \text { m; Partículas Inaláveis (MP10) são menores ou } \\
\text { iguais a 10 } \mu \text { m e as Partículas Inaláveis Finas (MP2,5) são menores ou iguais a 2,5 } \mu \text { m. }\end{array}$ \\
\hline Radiação & $\begin{array}{l}\text { Encontrados em automóveis, indústrias, pesticidas, corantes, fumaças de combustão } \\
\text { orgânica. Relacionados à diversos tipos de câncer, além de causar envelhecimento } \\
\text { extrínseco da pele, pigmentação e acne. }\end{array}$ \\
\hline radiação.
\end{tabular}




\begin{tabular}{|c|l|}
\hline Metais pesados & $\begin{array}{l}\text { Os metais pesados chumbo, cádmio e mercúrio são poluentes atmosféricos que } \\
\text { representam risco a saúde devido a seus aspectos relacionados com a bioacumulação, } \\
\text { derivados da queima dos combustíveis fósseis. }\end{array}$ \\
\hline $\begin{array}{c}\text { Tóxicos } \\
\text { relacionados ao } \\
\text { tráfego }\end{array}$ & $\begin{array}{l}\text { É a mistura de componentes poluentes derivados da emissão primária de veículos } \\
\text { movidos a diesel e gasolina. Contém dióxido de carbono (CO2), CO, NO, COV, PM, } \\
\text { chumbo e outros produtos químicos tóxicos, como formaldeído e 1,3butadieno. As } \\
\text { comunidades urbanas localizadas próximas de estradas possuem um alto nível de } \\
\text { poluente relacionado ao tráfego. }\end{array}$ \\
\hline
\end{tabular}

Fonte: Elaborado pelos autores.

\section{Ação da toxicidade da poluição na pele}

O mecanismo de ação dos poluentes que causam danos a pele ainda não está totalmente esclarecido, mas as evidências apontam quatro potenciais mecanismos deletérios sobre a pele: indução de cascata inflamatória, ativação de AhR (receptor de hidrocarboneto arílico), alterações da microflora da pele e geração de radicais livres [4].

Os radicais livres in vivo se formam a partir da ação catalítica de enzimas, como por exemplo, exposição a fatores exógenos (ozônio, radiações gama e ultravioleta, cigarros, poluentes, etc.) sendo altamente reativas, podendo causar alterações no organismo [6]. O ozônio resulta em danos oxidativos cumulativos no estrato córneo em caso de exposição crônica, gerando espécies de radicais livres. Diminui as defesas da pele e é capaz de esgotar as reservas antioxidantes enzimáticas (exemplo: Glutationa peroxidase, Glutationa redutase, superóxido dismutase e catalase) e não enzimáticas (exemplo: vitamina E, C e Glutationa). Estes mesmos radicais livre, por sua vez, ao interagirem facilmente com a membrana plasmática da derme, causam um desequilíbrio pró-oxidante/antioxidante iniciando uma cascata de peroxidação lipídica, e também, estimulam a liberação de mediadores próinflamatórios que adentram a pele através de neutrófilos e outras células fagocíticas, resultando em níveis aumentados de IL- $1 \beta$, IL- 6 e IL- 8 que ativam a quimiotaxia e a fagocitose de granulócitos. Desta forma, com a combinação destes processos se obtém como resultado a toxicidade direta e indireta da pele, gerando mais espécies reativas de oxigênio, formando, então, um ciclo vicioso do ozônio que esgota os níveis de ATP Sirtuinas 3 nas mitocôndrias, uma proteína envolvida na eliminação de radicais livres mitocondriais [7].

\section{A Dermatite Atópica}

A palavra "Dermatite" vem do grego "derma" (pele) e "iite" (inflamação). A Dermatite Atópica é uma doença inflamatória crônica e reincidente que acomete a pele, principalmente na primeira fase da infância, De acordo com o Estudo Internacional de Asma e Alergias na Infância, a maior ocorrência de Dermatite Atópica é apontada em crianças de 6 a 7 anos e de 13 a 14 anos de idade. Este estudo mostra que a doença está aumentando em países desenvolvidos e industrializados. [6].

A doença afeta $15-20 \%$ das crianças do mundo, e dessas de 10-20\% persistem até a vida adulta, sendo um percentual global de adultos de 9\% [8]

Gráfico 1. Relação da incidência da Dermatite Atópica de acordo com a idade.

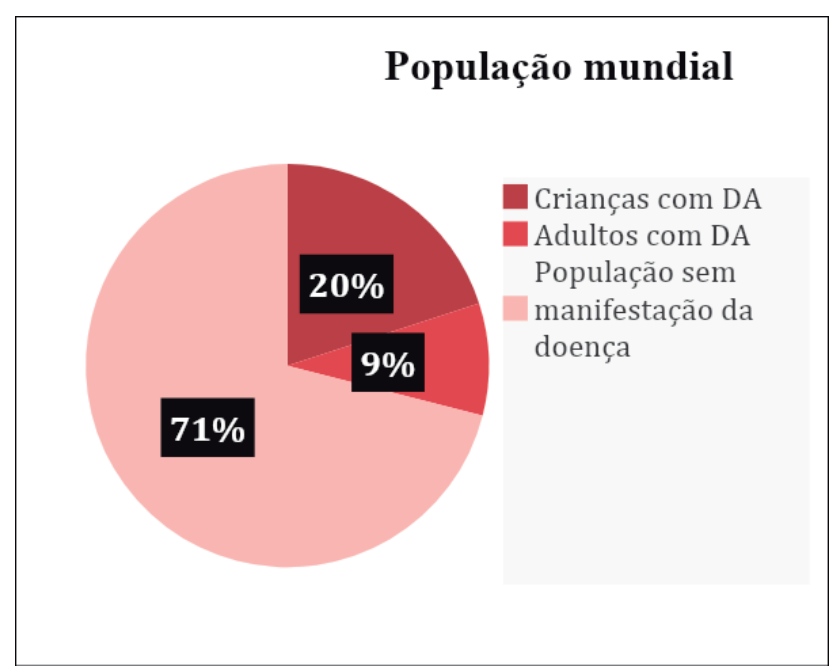

Fonte: Elaborado pelos autores.

Em $99 \%$ dos casos os pacientes sofrem de coceira diária, sendo em média $60 \%$ mais de 12 horas ao dia [9]. A Dermatite Atópica está relacionada com a predisposição genética e com estímulos ambientais. 
O risco de desenvolver é de 2 a 3 vezes maior quando um dos pais é atópico e de 3 a 5 vezes maior se ambos os pais forem atópicos [10].

A diversidade de poluentes com os quais convivemos diariamente tais como compostos orgânicos voláteis, formaldeído, tolueno, fumaça de tabaco, dióxido de nitrogênio e material particulado, atuam como fatores de risco para o desenvolvimento ou agravamento da Dermatite Atópica. Existe grande possibilidade de que esses poluentes possuam a capacidade de induzir o estresse oxidativo na pele, deste modo, ocorrendo a disfunção da barreira cutânea ou desregulação imunológica. [11].

A barreira epidémica é localizada na porção mais externa da epiderme, no estrato córneo. As camadas de corneócitos são conectados por córneo desmossomas e encaixadas em uma matriz intercelular enriquecida por lipídios [12].

Nos casos de Dermatite Atópica, ocorre a disfunção da barreira cutânea e descamação excessiva da pele por perda da conecção entre corneócitos e os desmossomas. Esta situação favorece a penetração de alérgenos, A perda de proteína Filagrina está relacionada com as mutações por perda de função de genes. O uso excessivo de detergentes e sabões podem promover danos a barreira cutânea e prejudicar a pele do paciente atópico de maneira considerável [6].

O desenvolvimento da Dermatite Atópica é induzido devido a predisposição genética, segundo alguns autores. Normalmente, os pacientes com D.A possuem defeitos na barreira cutânea, pois ocorre maior expressão de citocinas como IL-4 e IL-13, que desregulam a expressão de proteínas epidérmicas como Loricrina, Involucrina e Filagrina, indispensáveis para manutenção de água nas estruturas da epiderme e que determinam uma boa funcionalidade da barreira cutânea [13,14,15,33].

Duas grandes alterações ocorrem durante a Dermatite, a primeira é a disfunção da barreira epidérmica e a imunológica, sendo uma disfunção inata especialmente em queratinócitos e células de Langerhans e tendo a ativação linfocitária para desvio Th2 (linfócitos auxiliares tipo 2) [16].

As células de Langherans são estimuladas pelos antígenos na fase aguda, com resultante estimulação de linfócitos Th2, formando IL-4, IL-5 (causa a migração de eosinófilos) e IL-13 (indutora de crescimento celular). As interleucinas, por sua vez induzem os linfócitos B a sintetizarem IgE e inclusive expressão de moléculas de adesão vascular, VCAM-1, que são encarregados pela infiltração de eosinófilos e atenuação da produção de citocinas pelas células Th1. Já na fase crônica, temos a interação entre as células de Langherans e macrófagos. Como consequência, há liberação de IL-1, que estimula linfócitos Th2 a produzirem mais IL-4, IL13, IL-5 e agente liberador de histamina $[17,18]$.

\section{A Dermatite Atópica e a relação com a poluição e seus possíveis mecanismos de ação}

Sendo uma doença inflamatória cutânea comum na infância e adolescência, crônica e relacionada à atopia, existe predisposição a produzir anticorpos de imunoglobulina E (IgE), que pode ser provocada em resposta a quantidades mínimas de agentes irritantes como pólen, ácaros, alérgenos alimentares, perfumes, fumo, tabaco e poluentes encontrados no ar atmosférico, sendo a DA uma doença multifatorial [18].

Aproximadamente $70 \%$ dos pacientes com D.A grave desenvolve asma em comparação com 20-30\% dos pacientes com D.A leve e aproximadamente $8 \%$ da população geral. A gravidade da D.A correlaciona-se com o risco de desenvolver rinite e com níveis elevados de anticorpos IgE totais e específicos [19].

Gráfico 2. Relação entre a Dermatite Atópica e o desenvolvimento de doenças respiratórias.

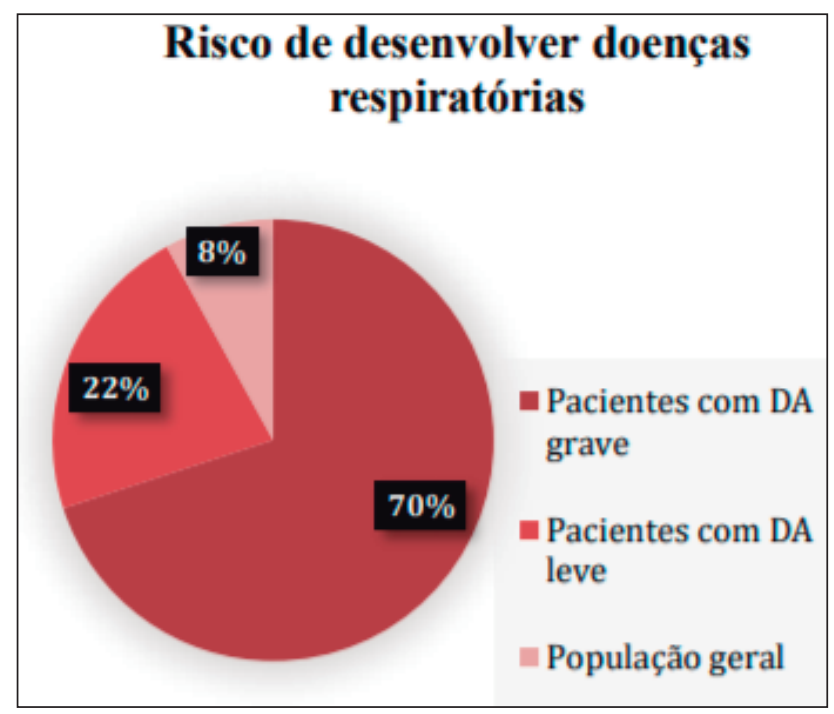

Fonte: Elaborado pelos autores.

O Brasil possui altos índices de doenças alérgicas em comparação com os outros países da América 
do Sul e do mundo. Essa incidência tem aumentado principalmente em cidades consideradas industrializados, entre os anos 1950 e 2000, mostrando uma relação entre a poluição atmosférica e o aumento de doenças alérgicas como asma, rinite e Dermatite Atópica, por exemplo [20].

A Dermatite Atópica possui potenciais fatores de risco para o seu desenvolvimento. Apesar de que o exato mecanismo de ação não esteja estabelecido atualmente, os poluentes atmosféricos são considerados iminentes para o seu surgimento. Através da poluição do ar ocorrem danos de proteínas, lipídios e DNA provindos da formação de espécies reativas de oxigênio que são geradas através de processos inflamatórios causados por disfunção biológica ou provenientes de alimentos. As espécies reativas de oxigênio são distribuídas em dois grupos designados como radicalares: hidroxila, superóxido, peroxila e alcoxila; e não-radicalares: oxigênio, peróxido de hidrogênio e ácido hipocloros [21,22,23].

A exposição da pele a poluentes ambientais causa desequilíbrios entre oxidantes e antioxidantes, este estresse oxidativo gera o agravamento dos sintomas e incidência da Dermatite Atópica, pois a barreira cutânea é afetada de forma direta. Em um estudo realizado com 75 adultos que apresentam o quadro de Dermatite Atópica foram submetidas amostras de biopsia em análises usando o ensaio espectrofotométrico de dinitrofenilhidrazina para mensurar as frações carbonílicas. Foi constatado que a distribuição e formação de dinitrofenilhidrazina estava aumentada nas lesões causadas por Dermatite Atópica; em conjunto foi observada a coloração mais acentuada nas camadas superficiais do estrato córneo. Este estudo concluiu que o dano oxidativo pode ser atribuído a exposição a oxidantes ambientais e que o aumento das espécies reativas de oxigênio provindos da poluição ambiental e luz ultravioleta podem induzir a irregularidade oxidativa às proteínas no estrado córneo, consequentemente ocasionando a disfunção da barreira cutânea e o agravamento da Dermatite Atópica [24].

A exposição a poluentes do ar afeta o desenvolvimento e a incidência da D.A e geram mecanismos de ação propostos como, por exemplo, as alterações epigenéticas e hipometilação do gene $\mathrm{CpG}$ da lifopoietinaestromal tímica, acometidas durante o período gestacional quando ocorrem exposição da mãe a fumaça de tabaco. As alterações restringem a quantidade de células $\mathrm{T}$ reguladoras ou aumentam a expressão da proteína lifopoietinaestromal tímica ocasionando à polarização de TH2. Após o nascimento, a criança entra em contato direto com diversos tipos de poluentes ambientais, que gera estresse oxidativo resultando em danos ao lipídio e proteínas. Os danos causados pela poluição ocorrem em fetos, bebês ou crianças em estágio de desenvolvimento ou perante predisposição genética; outra forma de exposição ocorre através da inalação ou ingestão destes poluentes presentes na atmosfera. Alguns estudos in vitro e experimentos em animais sugerem que a liberação de citocinas pró-inflamatórias não-alérgicas e indução de secreções e prurido resultam em sintomas relacionados com a coceira, ou o aumento na expressão de IL-4, deste modo contribuindo para o desenvolvimento da Dermatite Atópica [4].

A poluição atmosférica consiste na mistura de diversos agentes contaminantes particulados. O material particulado induz na pele o processo de estresse oxidativo, ocasionando disfunções no manto hidro lipídico e o desequilíbrio imunológico do paciente. $\mathrm{O}$ mecanismo de ação do material particulado consiste na formação de espécies reativas de oxigênio e a produção de citocinas que ativam o processo de inflamação, deste modo é possível relacionar os poluentes atmosféricos com as doenças cutâneas [24,25].

$\mathrm{Na}$ D.A, a pele é caracterizada pelo aspecto seco (xerose), devido à perda transepidérmica de água. Além disso, apresenta deficiência da proteína Filagrina, que tem função estrutural da pele e cerca de 50\% dos casos de Dermatite Atópica foram relacionadas com alterações do gene da Filagrina [26,33].

Prurido é sintoma muito comum em pacientes com D.A, pois a ele se deve as lesões na pele dos pacientes [27].

Muitos estudos relacionam a poluição com o agravamento da D.A, pois observa-se o crescimento da doença no mundo juntamente com o avanço da industrialização, além disso mudanças climáticas também estão associadas com essa patologia. Estudar a relação da poluição com a D.A ainda é um desafio, pois há poucos métodos para avaliar o efeito agudo da poluição atmosférica com os sintomas da D.A $[28,29]$.

Ativos antipoluição que podem ser usados na pesquisa e desenvolvimento industrial (P\&D).

Atualmente é possível encontrar uma gama de ativos com a finalidade antipoluição. Foi realizada uma pesquisa objetivando verificar a origem, mecanismo de ação e a de diferentes ativos. 
Os dados citados na tabela abordam informações gerais sobre os ativos disponíveis no mercado.

Tabela 2. Dados de ativos antipoluição de origem botânica e sintética, mecanismo de ação e as possíveis aplicabilidades para a pesquisa e desenvolvimento de dermocosméticos.

\begin{tabular}{|c|c|c|c|c|}
\hline Ativo Empresa & Origem & Uso & Incorporado em & Benefícios \\
\hline $\begin{array}{l}\text { Apolluskin }^{\circ} \\
\quad \text { (Silab) }\end{array}$ & $\begin{array}{c}\text { Botânico Withania Somnifera } \\
\text { Root Extract }\end{array}$ & Tópico & Emulsões e géis. & $\begin{array}{l}\text { Limita inflamação e a } \\
\text { oxidação de proteínas. } \\
\text { Reduz atividade de } \\
\text { AhR. Inibe inflamação } \\
\text { pela redução de } \\
\text { IL-1, mediadora de } \\
\text { inflamação. Possui } \\
\text { forte ação antioxidante. }\end{array}$ \\
\hline $\begin{array}{l}\text { City Guard }+^{\circ} \\
\quad \text { (Codif) }\end{array}$ & Marinha Microalga & Tópico & Gel. & $\begin{array}{l}\text { Oligoalginato de } \\
\text { massa molecular } \\
\text { elevada que atua como } \\
\text { uma segunda pele, } \\
\text { prevenindo que os } \\
\text { poluentes permeiem } \\
\text { a pele; proteção à } \\
\text { barreira cutânea. }\end{array}$ \\
\hline $\begin{array}{l}\text { City Stem } \\
\text { (Sederma) }\end{array}$ & $\begin{array}{c}\text { Botânico Marrubium Vulgare } \\
\text { Extract }\end{array}$ & Tópico & $\begin{array}{l}\text { Emulsões, } \\
\text { séruns, géis. }\end{array}$ & $\begin{array}{l}\text { Protege e fortalece } \\
\text { a função barreira, } \\
\text { removendo espécies } \\
\text { oxidantes tóxicas. } \\
\text { Protege da penetração } \\
\text { de poluentes. Forte } \\
\text { ação antioxidante. }\end{array}$ \\
\hline $\begin{array}{l}\text { Cobioage }^{\bullet} \\
\text { (Cobiosa) }\end{array}$ & $\begin{array}{l}\text { Botânico Extrato da vagem de } \\
\text { Caesalpiniaspinosa }\end{array}$ & Tópico & Emulsões e géis. & $\begin{array}{l}\text { O extrato da planta } \\
\text { apresenta forte ação } \\
\text { antioxidante; possui } \\
\text { ação antiglicosilação. } \\
\text { Protege contra } \\
\text { poluentes e fumaça de } \\
\text { cigarro. }\end{array}$ \\
\hline $\begin{array}{l}\text { Cobiobright }^{\oplus} \\
\text { (Cobiosa) }^{\text {Cobion }}\end{array}$ & $\begin{array}{c}\text { Botânico } \\
\text { Pouterialucuma }\end{array}$ & Tópico & Emulsões e géis. & $\begin{array}{l}\text { Existe uma correlação } \\
\text { entre o óxido } \\
\text { nitroso, encontrado } \\
\text { nos poluentes e as } \\
\text { manchas, causando } \\
\text { estresse oxidativo. } \\
\text { Ativo rico em } \\
\text { antioxidantes, } \\
\text { carotenoides, vitaminas } \\
\text { e niacina. Atua } \\
\text { prevenindo as manchas } \\
\text { decorrentes dos } \\
\text { processos inflamatórios } \\
\text { deflagrados pelos } \\
\text { poluentes. }\end{array}$ \\
\hline
\end{tabular}




\begin{tabular}{|c|c|c|c|c|}
\hline $\begin{array}{l}\text { Eps White } \mathrm{P}^{\circledast} \\
\text { (Codif) }\end{array}$ & $\begin{array}{c}\text { Sintético Fenoxietanol + Álcool } \\
\text { Fenetílico }\end{array}$ & Tópico & $\begin{array}{l}\text { Emulsões, géis e } \\
\text { séruns. }\end{array}$ & $\begin{array}{l}\text { Polímero de açúcar } \\
\text { capaz de interagir } \\
\text { com a formação de } \\
\text { sinapses pigmentares. } \\
\text { Pode ser usado em } \\
\text { formulações para o } \\
\text { tratamento de manchas } \\
\text { escuras causadas por } \\
\text { poluição. }\end{array}$ \\
\hline $\begin{array}{l}\text { Ferment'ActiveGoji } \\
\quad \text { (Greentech) }{ }^{\circledR}\end{array}$ & $\begin{array}{l}\text { Botânico Lycium } \\
\text { Chinense Fruit } \\
\text { Extract }\end{array}$ & Tópico & Emulsões e géis. & $\begin{array}{l}\text { Protege contra radicais } \\
\text { livres; previne o } \\
\text { estresse oxidativo; } \\
\text { fortalece as defesas } \\
\text { contra fatores } \\
\text { ambientais. }\end{array}$ \\
\hline Filmexel $^{\oplus}($ Silab $)$ & $\begin{array}{c}\text { Botânico Kappaphycus } \\
\text { Alvarezii Extract } \\
\text { (and) Caesalpinia Spinosa Fruit } \\
\text { Extract }\end{array}$ & Tópico & Emulsões e géis. & $\begin{array}{l}\text { Biopolímero formador } \\
\text { de filme mimético } \\
\text { a barreira cutânea, } \\
\text { resistente, flexível e } \\
\text { não oclusivo. Protege } \\
\text { contra agentes } \\
\text { exógenos como } \\
\text { poluentes, alergênicos } \\
\text { e irritantes (inclui os } \\
\text { tensoativos) }\end{array}$ \\
\hline $\begin{array}{l}\text { HerbaShield URB }{ }^{\circledR} \\
\text { (LipoidKosmetik) }\end{array}$ & $\begin{array}{c}\text { Botânico Nasturtium } \\
\text { Officinale }+ \text { Equisetum Arvense } \\
\text { Extract }+ \text { Urtica Dioica }\end{array}$ & Tópico & Emulsões. & $\begin{array}{l}\text { Cuidados com a pele na } \\
\text { proteção antipoluição; } \\
\text { tratamentos de } \\
\text { desintoxicação; } \\
\text { proteção urbana ou } \\
\text { ambiental. }\end{array}$ \\
\hline $\begin{array}{l}\text { I-Defender }^{\oplus} \\
\text { (Cobiosa) }\end{array}$ & $\begin{array}{c}\text { Marinha } \\
\text { Glicogênio Marinho }\end{array}$ & Tópica & Emulsões e géis. & $\begin{array}{l}\text { Agente Antiestresse; } \\
\text { reduz a liberação } \\
\text { de radicais livres; } \\
\text { protege a integridade e } \\
\text { estabilidade do DNA; } \\
\text { age como uma barreira } \\
\text { contra radiação } \\
\text { eletromagnética, outro } \\
\text { tipo de poluição; evita } \\
\text { o desenvolvimento de } \\
\text { processos inflamatórios } \\
\text { da pele. }\end{array}$ \\
\hline $\begin{array}{l}\text { Mitokinyl }^{\oplus} \\
\quad \text { (Silab) }\end{array}$ & Levedura (Pichiaheedii) & Tópico & Emulsões e géis. & $\begin{array}{l}\text { Promove a desativação } \\
\text { do receptor de } \\
\text { hidrocarboneto arílico } \\
\text { e a normalização da } \\
\text { síntese de mitoquina, } \\
\text { principais caminhos } \\
\text { contra a ação de } \\
\text { poluentes na pele. }\end{array}$ \\
\hline
\end{tabular}




\begin{tabular}{|c|c|c|c|c|}
\hline $\begin{array}{c}\mathrm{PGT}^{\circ} \\
(\text { Exsymol })\end{array}$ & $\begin{array}{c}\text { Sintético } \\
\text { PyroglutamylamidoethylIndole }\end{array}$ & Tópico & $\begin{array}{l}\text { Emulsões, géis e } \\
\text { séruns. }\end{array}$ & $\begin{array}{l}\text { Possui forte ação } \\
\text { antioxidante. Aumenta } \\
\text { a imunidade da pele } \\
\text { e a resistência contra } \\
\text { agressões externas, } \\
\text { incluindo a poluição e } \\
\text { a fumaça. }\end{array}$ \\
\hline $\begin{array}{l}\text { POLLUSTOP }^{\circledast} \\
\quad \text { (Solabia) }\end{array}$ & $\begin{array}{c}\text { Sintético } \\
\text { Biosaccharide Gum-4 anda } \\
\text { 1,2,Hexanediol }\end{array}$ & Tópico & Emulsões e géis. & $\begin{array}{l}\text { Polissacarídeo de alta } \\
\text { massa molecular que } \\
\text { age como barreira } \\
\text { contra agentes } \\
\text { poluentes, metais } \\
\text { pesados, partículas de } \\
\text { carbono e partículas } \\
\text { suspensas. Limita } \\
\text { danos como estresse } \\
\text { oxidativo, inflamação } \\
\text { e toxicidade celular. } \\
\text { Protege o manto hidro } \\
\text { lipídico. }\end{array}$ \\
\hline $\begin{array}{c}\text { Pollushield }^{\bullet} \\
\text { (Lipotec) }\end{array}$ & $\begin{array}{c}\text { Sintético } \\
\text { Propanediol } \\
\text { diisopropyladipato, Lecithin, } \\
\text { entre outros }\end{array}$ & Tópico & Emulsões e géis. & $\begin{array}{l}\text { Contém polímero com } \\
\text { capacidade quelante de } \\
\text { metais tóxicos. Elimina } \\
\text { radicais livres. Evita } \\
\text { estresse oxidativo. }\end{array}$ \\
\hline $\begin{array}{c}\text { SkinBlitz }^{\circledast} \\
\text { (Chemyunion) }\end{array}$ & $\begin{array}{c}\text { Botânico } \\
\text { Redes poliméricas de } \\
\text { polissacarídeos naturais } \\
\text { derivadas da sálvia, trealose e } \\
\text { galactoarabinas. }\end{array}$ & Tópico & $\begin{array}{l}\text { Emulsões, géis } \\
\text { e soros para } \\
\text { proteção da pele } \\
\text { contra a poluição. }\end{array}$ & $\begin{array}{l}\text { Reduz a permeação de } \\
\text { agentes poluidores em } \\
65 \% \text {; protege o DNA } \\
\text { das células expostas à } \\
\text { poluição. } \\
\text { Inibi o envelhecimento } \\
\text { prematuro; inibe a } \\
\text { hiperpigmentação } \\
\text { causada pela poluição; } \\
\text { reduz os níveis de } \\
\text { biomarcadores de } \\
\text { estresse ambiental em } \\
55 \% \text { (HSP70). }\end{array}$ \\
\hline $\begin{array}{l}\text { Urbalys }^{\oplus} \\
\text { (Greentech) }\end{array}$ & $\begin{array}{c}\text { Botânico } \\
\text { Schisandrachinensis }\end{array}$ & Tópico & Emulsões e géis. & $\begin{array}{l}\text { A planta } \\
\text { Schisandrachinensis } \\
\text { possui alto teor } \\
\text { de ligninas. Estas } \\
\text { ligninas são capazes } \\
\text { de ativar as defesas } \\
\text { celulares e prevenir } \\
\text { danos induzidos por } \\
\text { radicais livres. Efeito } \\
\text { antioxidante e anti- } \\
\text { inflamatório. Previne } \\
\text { disfunção da barreira } \\
\text { cutâna, reduz perda de } \\
\text { água transepidermal. } \\
\text { Limita o impacto } \\
\text { oclusivo dos agentes } \\
\text { poluentes. }\end{array}$ \\
\hline
\end{tabular}


Fonte: Adaptado de Souza, V.M. Antunes, D.J., 2016 [31]

Gráfico 3: Comparação entre a origem dos ativos antipoluição do mercado atual

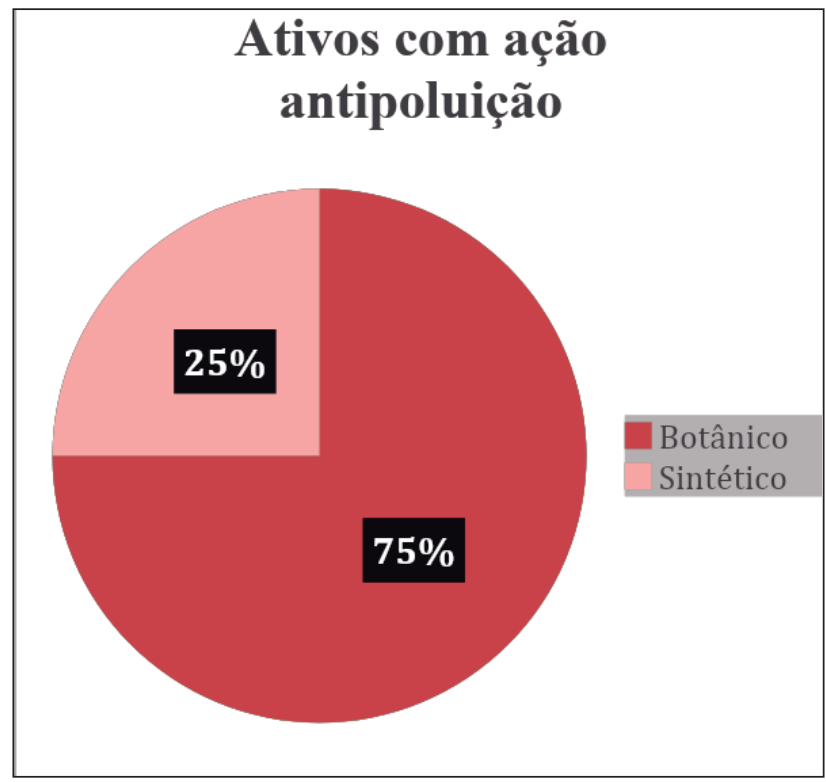

Fonte: Elaborado pelos autores

A partir da pesquisa realizada sobre D.A, os poluentes e ativos que atuam neste mecanismo, sugerimos algumas combinações de ativos para formular um dermocosmético com o conceito antipoluição e que agregue um benefício aos pacientes em relação ao tratamento da Dermatite Atópica, trazendo melhoria na qualidade de vida desses pacientes.
Tabela 3. Sugestão de fórmula para aplicação na braços e pernas após banho.

Objetivo: formular com agentes filmógenos, antioxidantes, quelante de metais tóxicos e que possam proporcionar melhora da imunidade da pele. Veículo derivado de óleo de oliva.

\begin{tabular}{|c|l|l|c|}
\hline \multicolumn{4}{|c|}{ Creme Hidratante Antipoluição Corporal } \\
\hline \multicolumn{1}{|c|}{ Ingrediente } & \multicolumn{1}{|c|}{ INCI Name } & \multicolumn{1}{c|}{ Função } & Concentração \\
\hline Filmexel $^{\bullet}$ & $\begin{array}{l}\text { Kappaphycus Alvarezii } \\
\text { Extract (and) Caesalpinia } \\
\text { Spinosa Fruit Extract }\end{array}$ & $\begin{array}{l}\text { Formador de filme mimético } \\
\text { à barreira cutânea. Proteção } \\
\text { contra poluentes, alérgenos e } \\
\text { agentes irritantes. }\end{array}$ & $1,0 \%$ \\
\hline Pollushield & $\begin{array}{l}\text { Water; Propanediol; } \\
\text { Diisopropyl Adipate; } \\
\text { Lecithin; Acrylic cid / } \\
\text { Acrylamidomethyl Propane } \\
\text { Sulfonic; Acid Copolymer } \\
; \text { Dimethylmethoxy } \\
\text { Chromanol; Glyceryl } \\
\text { Caprylate; Xanthan Gum. }\end{array}$ & $\begin{array}{l}\text { Aumenta as defesas } \\
\text { antioxidantes contra poluição } \\
\text { urbana. Quela metais tóxicos. } \\
\text { Elimina radicais livres }\end{array}$ & $5,0 \%$ \\
\hline PGT1 & $\begin{array}{l}\text { Pyroglutamylamidoethyl } \\
\text { Indole (and) Butylene Glycol } \\
\text { (and) Water }\end{array}$ & $\begin{array}{l}\text { Possui forte ação antioxidantes. } \\
\text { Aumenta a imunidade da pele } \\
\text { e a resistência contra agressões } \\
\text { externas, incluindo a poluição e } \\
\text { a fumaça. }\end{array}$ & $2,0 \%$ \\
\hline
\end{tabular}




\begin{tabular}{|l|l|l|c|}
\hline $\begin{array}{l}\text { Óleo vegetal de } \\
\text { gérmem de trigo }\end{array}$ & Triticum Vulgare Germ Oil & $\begin{array}{l}\text { Óleo vegetal rico em vitaminas } \\
\text { A e E. Proporciona benefícios } \\
\text { superiores a pele com DA. }\end{array}$ & $5,0 \%$ \\
\hline $\begin{array}{l}\text { Emulsão Olivem } \\
1000 \text { qsp }\end{array}$ & Veículo & $100 \%$ \\
\hline
\end{tabular}

Fonte: Elaborado pelos autores.

Tabela 4. Sugestão de fórmula para aplicação em face, pescoço e colo antes do FPS. Objetivo: formular com agentes protetores de barreira cutânea, que pro- tejam contra os danos ao DNA das células expostas aos poluentes e que protejam contra o envelhecimento, inibindo manchas e estresse oxidativo.

\begin{tabular}{|c|c|c|c|}
\hline \multicolumn{4}{|c|}{ Sérum Facial Antipoluentes } \\
\hline Ingrediente & INCI Name & Função & Concentração \\
\hline Urbalys $^{\circledast}$ & $\begin{array}{l}\text { Water (and) Propane- } \\
\text { diol (and) Schisandra } \\
\text { Chinensis Fruit Extract. }\end{array}$ & $\begin{array}{l}\text { Prevenir radicais livres e } \\
\text { danos da função da } \\
\text { barreira reduz a perda de } \\
\text { água transepidermal. }\end{array}$ & $2,0 \%$ \\
\hline SkinBlitz ${ }^{\odot}$ & $\begin{array}{l}\text { Water; Salvia Hispanica } \\
\text { Seed Extract; Trehalose; } \\
\text { Galactoarabinan; Glyc- } \\
\text { erin; Xylitol; Sodium } \\
\text { Phosphate; Sorbitol. }\end{array}$ & $\begin{array}{l}\text { Reduz a permeação de } \\
\text { agentes poluidores. Pro- } \\
\text { tege o DNA das células } \\
\text { expostas à poluição, } \\
\text { inibindo o envelhecimen- } \\
\text { to prematuro e inibe a hi- } \\
\text { perpigmentação causada } \\
\text { pelos poluentes. }\end{array}$ & $3,0 \%$ \\
\hline Sérum qsp & & Veículo & $100 \%$ \\
\hline
\end{tabular}

Fonte: Elaborado pelos autores.

Tabela 5. Veículo Olivem 1000.

\begin{tabular}{|l|c|c|c|}
\hline Fase/Ingrediente & INCI Name & Função & Concentração \\
\hline A.Olivem 1000 & $\begin{array}{c}\text { Cetearyl Olivate; Sorbitan } \\
\text { Olivate }\end{array}$ & $\begin{array}{c}\text { Cera auto } \\
\text { emulsionante }\end{array}$ & $10 \%$ \\
\hline A.Microcare PHG & $\begin{array}{c}\text { Caprylyl Glycol; } \\
\text { Phenoxiethanol }\end{array}$ & Conservante & $0,1 \%$ \\
\hline A.Crodamol GTCC & Craprylic/Capric Triglyceride & Emoliente & $2,0 \%$ \\
\hline B. Pentilenoglicol & Pentilyne Glycol & Umectante & $0,5 \%$ \\
\hline B. EDTA & Dissodium Edta & Quelante & $0,1 \%$ \\
\hline B.Água purificada qsp & Water & Veículo & \\
\hline
\end{tabular}

Fonte: Elaborado pelos autores. 
Técnica de preparo: Aquecer a fase $\mathrm{A}$ à $75^{\circ} \mathrm{C}$; Aquecer a fase $\mathrm{B}$ à $75^{\circ} \mathrm{C}$; Incorporar as duas fases com agitação constante até $40^{\circ} \mathrm{C}$; Incorporar os ativos selecionados.

Tabela 6. Veículo Sérum.

\begin{tabular}{|c|c|c|c|c|}
\hline Fas & /Ingrediente & INCI Name & Função & Concentração \\
\hline A. & Lecigel & $\begin{array}{l}\text { Sodium Acrylates } \\
\text { Copolymer Lecithin }\end{array}$ & $\begin{array}{l}\text { Agente gelificante com } \\
\text { propriedades emulsionante. }\end{array}$ & $1,8 \%$ \\
\hline $\begin{array}{l}\text { A. } \\
\text { PHG }\end{array}$ & Microcare & $\begin{array}{l}\text { CaprylylGlycol; } \\
\text { Phenoxiethanol }\end{array}$ & Conservante & $0,1 \%$ \\
\hline A. & Água & Water & Veículo & Qsp 100\% \\
\hline
\end{tabular}

Fonte: Elaborado pelos autores.

Técnica de preparo: Incorporar o conservante na água e homogeneizar; Incorporar o agente gelificante à frio e homogeneizar; Incorporar os ativos selecionados.

\section{Conclusão}

Com o aumento da poluição nos países industrializados, observa-se o aumento no número de casos de Dermatite Atópica. Apesar de ser uma doença de manifestação genética, o abalo no manto hidro lipídico causado pelas partículas dos poluentes, o aumento do estresse oxidativo e dos radicais livres pode interferir negativamente e piorar os casos de D.A. Os agentes poluentes proporcionam danos nas proteínas, lipídios e DNA, causando disfunção biológica.

O levantamento dos dados demonstra a necessidade de tratamentos diferenciados para esta patologia e a importância do desenvolvimento de dermocosméticos com ativos que possam proteger ou tratar a pele contra esses agentes agressores.

Baseado nessas pesquisas, podemos observar que os ativos botânicos são considerados tendência no mercado mundial de tratamento e cuidados dermatológicos, principalmente com o direcionamento ao tratamento de doenças de pele relacionadas com a poluição.

No início do ano de 2016, pesquisadores deflagraram o alerta para a necessidade de observar as questões referentes as partículas e sua atuação e manifestação na pele atópica. Desde então, vários ativos foram pesquisados e melhorados em termos de atuação.

Os ativos de primeira geração eram basicamente formadores de filme e conseguiam absorver toxinas provenientes dos agentes poluentes. O ativo Filme-
$\mathrm{xel}^{\circledR}$ foi o primeiro ativo antipoluição a ser usado na Europa e no Brasil. Com o avanço das pesquisas, chegaram ao mercado os ativos antipoluição que quelam metais pesados e estimulam aos endoantioxidantes, conhecidos como ativos da segunda geração de antipoluentes. Em 2018 chegaram os ativos da terceira geração contra os malefícios dos poluentes, e que atuam fortalecendo e aumentando a imunidade da barreira cutânea, prevenindo estresse oxidativo e diminuindo a inflamação (<IL-1,IL-6,PGE-2). A proposta sequencial destes ativos pode ser uma alternativa para melhorar as condições da pele, do paciente com D.A. As propostas de formulações contidas nesta revisão possuem como objetivo estimular a área de pesquisa e desenvolvido em dermocosméticos para um olhar curioso aos ativos antipoluição e que atuem no fortalecimento das questões da pele, além de melhorar a qualidade de vida dos pacientes com Dermatite Atópica. No entanto, sugerimos a continuação do estudo farmacotécnicos e de estabilidade para creditar estas fórmulas na atuação sugerida pela pesquisa realizada.

\section{Referências}

1. GARBACCIO, JULIANA LADEIRA; FERREIRA, AMANDA DOMINGOS; PEREIRA, AMANDA LAÎS GONÇALVES GAMA. Self-skincare knowledge and practice described by elderly persons in the mid-west of Minas Gerais. Revista Brasileira de Geriatria e Gerontologia, Rio de Janeiro, v. 19, n. 1, jan./fev. 2016. http://www.scielo.br/scielo.php?scrip$\mathrm{t}=$ sci_arttext\&pid=S1809-98232016000100045.

2. DOMANSKY RC, BORGES EL. Manual para prevenção de lesões de pele: recomendações baseadas em evidência. $2^{a}$ ed. Rio de Janeiro: Rubio; 2014. 
3.THE NEW ENGLAND JOURNAL OF MEDICINE. Pathophysiology of premature skin aging induced by ultraviolet light. https://www.nejm.org/ doi/10.1056/nejm199711133372003? url ver $=z 39.88-$

4. DRENO, E. ARAVIISKAIA E. BERARDESCA T. BIEBER G. GONTIJO M. SANCHEZ VIERA L. MARROT B. CHUBERRE B. The impact of airborne pollution on skin. Journal of the european academy of dermatology and venereology. Cidade, v.00, n.11, p.111-222, jan. 2012.

https://onlinelibrary.wiley.com/doi/full/10.1111/ jdv. 15583.

5. WILLIAMS, H., STEWART, A., VON MUTIUS, E., COOKSON, W., AND ANDERSON, H.R. International Study of Asthma and Allergies in Childhood (ISAAC) Phase One and Three Study Groups. Is eczema really on the increase worldwide? J Allergy Clin Immunol. 2008; 121: 947-954.e15.

6. LEUNG, D. Y. M. ET AL. The role of air pollutants in atopic dermatitis. Clinical reviews in allergy and immunology, Seoul, Korea, v. 134, n. 5, p. 993-999, nov. 2014.

7. BIEBER, T. Atopicdermatitis. $\mathrm{N}$ Engl J Med. 2008; 358: 1483-1494

8.. NUTTEN S. Atopic Dermatitis: Global Epidemiology and Risk Factors. Ann NutrMetab 2015.

9. SIMPSON EL ET AL. Patient Burden of Moderate to Severe Atopic Dermatitis (Ad): Insights from a Phase $2 b$ Clinical Trial of Dupilumab in Adults. Jam Acad Dermatol. 2016.

10. EICHENFIELDLF et.al. Guidelines of Care for the Management of Atopic Dermatitis. Section 1. Diagnosis and Assessment of Atopic Dermatitis. Jam Acad Dermatol. 2014.

11. CORK, M.J., DANBY, S.G., VASILOPOULOS, Y., HADGRAFT, J., LANE, M.E., MOUSTAFA, $M$. Epidermal barrier dysfunction in atopic dermatitis. J Invest Dermatol. 2009; 129: 1892-1908.

12. HOWELL, M.D., FAIRCHILD, H.R., KIM, B.E., BIN, L., BOGUNIEWICZ, M., REDZIC, J.S. Th2 cytokines act on S100/A11 to downregulate keratinocyte differentiation. J Invest Dermatol. 2008; 128: 2248-2258

13. HOWELL, M.D., KIM, B.E., GAO, P., GRANT, A.V., BOGUNIEWICZ, M., DEBENEDETTO, A. Cytokine modulation of atopic dermatitis filaggrin skin expression. J Allergy Clin Immunol. 2007; 120: 150-155.

14. KIM, B.E., LEUNG, D.Y., BOGUNIEWICZ,
M., AND HOWELL, M.D. Loricrin and involucrin expression is down-regulated by Th2 cytokines through STAT-6. Clin. Immunol. 2008; 126: 332-337

15. SIMÃO, HELIO M. Dermatite Atópica. 2014.

http://www.sbp.com.br/fileadmin/user_upload/ pdfs/dermatite at $\%$ c3\%93pica atualiza\%c3\%87\%c3\%830 em.pdf.

16. THOMSEN, S. FRANCIS. Atopic Dermatitis: Natural History, Diagnosis, and Treatment. https:// www.ncbi.nlm.nih.gov/pmc/articles/pmc4004110/

17. ARTIGOS DE ASMA, ALERGIA E IMUNOLOGIA. Guia prático de atualização em dermatite atópica. https://www.sbp.com.br/fileadmin/user upload/consenso - dermatite atopica_-vol_1_n_2 a04 1.pdf.

18. BOWLER, R.P. AND CRAPO, J.D. Oxidative stress in allergic respiratory diseases. J Allergy Clin. Immunol. 2002; 110: 349-356.

19. BANTZSK ET AL. THE ATOPIC MARCH: Progression from atopic dermatitis to allergic rhinitis and asthma. J Clin. Cell Immunol. 2014.

20. JOSÉ OTÁVIO BATISTA LEITE; PEREIRA, BOSCOLLI BARBOSA. Doenças da pele relacionadas à poluição do ar: uma revisão sistemática. Jornal of Health and Biologinal Sciences, [S.L], v. 5, n. 2, p. 171-177, fev./24. 03.

21. SCHWAB L., GORONCY L., PALANIYANDI S., GAUTAM S., TRIANTAFYLLOPOULOU A., MOCSAI A., REICHARDT W., KARLSSON F.J., RADHAKRISHNAN S.V., HANKE K. Neutrophil granulocytes recruited upon translocation of intestinal bacteria enhance graft-versus-host disease via tissue damage. Nat. Med. 2014; 20:648-654. doi: 10.1038/nm.3517.

22. HALLIWELL B, GUTTERIDGE JMC. Free radicals in biology and medicine. 2e ed. Oxford, UK: Clarendon, 1989.

23. NIWA, Y., SUMI, H., KAWAHIRA, K., TERASHIMA, T., NAKAMURA, T., AND AKAMAT$\mathrm{SU}, \mathrm{H}$. Protein oxidative damage in the stratum corneum: Evidence for a link between environmental oxidants and the changing prevalence and nature of atopic dermatitis in Japan. Br J Dermatol. 2003; 149: 248-254.

24. CASTRO, M. ANA PAUlA. Dermatite atópica na Infância. RBM set V 69 Especial Pediatria. http://www.moreirajr.com.br/revistas.asp?id materia $=5129 \&$ fase $=$ imprime.

25. SIMÃO, HELIO M. Dermatite Atópica. 2014. 
http://www.sbp.com.br/fileadmin/user upload/ pdfs/dermatite at $\%$ c3\%93pica atualiza $\%$ c3\% $87 \%$ c3\%83o em.pdf.

26. PAULA, C, C, Quando a pele fala: Investigação sobre as fantasias e construção da parentalidade em pais de crianças com dermatite atópica. https://www.teses.usp.br/teses/disponiveis/47/47131/ tde-24092015-111916/publico/paula corrigida.pdf

27. YOUNG-MIN KIM, JIHYUN KIM, YOUNGSHIN HAN, BYOUNG-HAK JEON, HAE-KWAN CHEONG, AND KANGMO AHN. Short-term effects of weather and air pollution on atopic dermatitis symptoms in children: a panel study in korea. https://www.ncbi.nlm.nih.gov/pmc/articles/ pmc5383262/.

28. PENARD-MORAND C, RAHERISON C, CHARPIN D, KOPFERSCHMITT C, LAVAUD F, CAILLAUD D. Long-term exposure to close-proximity air pollution and asthma and allergies in urban children. 2010. https://erj.ersjournals.com/content $/ 36 / 1 / 33$.

29. INDIAN JOURNAL OF DERMATOLOGY VENEREOLOGY AND LEPROLOGY. Effects of air pollution on the skin: a review. http://www.ijdvl.com/article.asp?issn $=0378-6323$; year $=2017 ;$ volume $=83$; issue $=4$; spage $=415$; epage $=423$; aulast $=$ puri

30. PENG FET AL. Exposure to fine particulate matter associated with senile lentigo in Chinese women: a cross-sectional study. 2016. https://www. ncbi.nlm.nih.gov/pubmed/27593207.

31. SOUZA, V. M. D; JUNIOR, DANIEL ANTUNES. Ativos Dermatológicos: Dermocosméticos e Nutracêuticos. 9. ed. 2016: Daniel Antunes, 2016.

32. YOUNG-MIN KIM, JIHYUN KIM, YOUNGSHING HAN, BYOUNG- HAK JEON, HAC-HAWN CHEONG, KANGMOAHN. Short-term effects of weather and air pollution on atopic dermatitis symptoms in children: A panel study in Korea; 2016. https://journals.plos.org/plosone/article?id=10.1371/ journal.pone.0175229.

33. VISSER MJ, LANDECK L, CAMPBELL LE, MCLEAN WHI, WEIDINGER S, CALKOEN F. Impact of atopic dermatitis and loss-of-function mutations in the filaggrin gene on the development of occupational irritant contact dermatites; 2016. https://www.ncbi.nlm.nih.gov/pubmed/23039796. 